\title{
Interaction between Mycobacterium avium subsp. paratuberculosis and environmental protozoa Lynne Whan ${ }^{1}$, Irene R Grant ${ }^{1}$ and Michael T Rowe*1,2
}

\author{
Address: ${ }^{1}$ Department of Food Science, Queen's University Belfast, Newforge Lane, Belfast BT9 5PX, Northern Ireland, UK and ${ }^{2}$ Food Microbiology \\ Branch, Agriculture, Food and Environmental Science Division, Agri-Food and Biosciences Institute, Newforge Lane, Belfast BT9 5PX, Northern \\ Ireland, UK \\ Email: Lynne Whan - lynnewhan@hotmail.com; Irene R Grant - i.grant@qub.ac.uk; Michael T Rowe* - michael.rowe@afbini.gov.uk \\ * Corresponding author
}

Published: 13 July 2006

BMC Microbiology 2006, 6:63 doi:10.1 |86/147|-2180-6-63
Received: 28 April 2006

Accepted: 13 July 2006

This article is available from: http://www.biomedcentral.com/|47|-2/80/6/63

(C) 2006 Whan et al; licensee BioMed Central Ltd.

This is an Open Access article distributed under the terms of the Creative Commons Attribution License (http://creativecommons.org/licenses/by/2.0), which permits unrestricted use, distribution, and reproduction in any medium, provided the original work is properly cited.

\begin{abstract}
Background: Interactions between Mycobacterium avium subsp. paratuberculosis (Map) and freeliving protozoa in water are likely to occur in nature. The potential impact of ingestion of Map by two naturally occurring Acanthamoeba spp. on this pathogen's survival and chlorine resistance was investigated.

Results: Between 4.6 and $9.1 \%$ of spiked populations of three Map strains (NCTC 8578, B2 and ATCC 19698), which had been added at a multiplicity of infection of I0:I, were ingested by Acanthamoeba castellanii CCAP I50I/IB and A. polyphaga CCAP I50I/3B during co-culture for $3 \mathrm{~h}$ at $25^{\circ} \mathrm{C}$. Map cells were observed to be present within the vacuoles of the amoebae by acid-fast staining. During extended co-culture of Map NCTC 8578 at $25^{\circ} \mathrm{C}$ for $24 \mathrm{~d}$ with both A. castellanii and $A$. polyphaga Map numbers did not change significantly during the first 7 days of incubation, however a I-I.5 $\log _{10}$ increase in Map numbers was observed between days 7 and 24 within both Acanthamoeba spp. Ingested Map cells were shown to be more resistant to chlorine inactivation than free Map. Exposure to $2 \mu \mathrm{g} / \mathrm{ml}$ chlorine for $30 \mathrm{~min}$ resulted in a $\log _{10}$ reduction of 0.94 in ingested Map but a $\log _{10}$ reduction of 1.73 in free $\operatorname{Map}(\mathrm{p}<0.00 \mathrm{I})$.
\end{abstract}

Conclusion: This study demonstrated that ingestion of Map by and survival and multiplication of Map within Acanthamoeba spp. is possible, and that Map cells ingested by amoebae are more resistant to inactivation by chlorine than free Map cells. These findings have implications with respect to the efficacy of chlorination applied to Map infected surface waters.

\section{Background}

Mycobacterium avium subsp. paratuberculosis (Map) is the known cause of Johne's disease of wild and domestic ruminants, in particular dairy cattle [1]. Although cattle are usually infected with Map during the first six months of life, via the faecal oral route, clinical signs, such as diarrhoea, emaciation and dehydration, usually develop only after a 3-5 year incubation period [2]. Despite the impor- tance of Johne's disease, both from an animal welfare and agro-economic perspective, the molecular mechanisms that are involved in the entry and survival of Map in the host are only poorly characterised [3]. However, it is now generally accepted that the persistence of Map in host macrophages is crucial to the establishment and progression of the disease [1]. 
In addition to its clear veterinary importance Map may have a more direct human impact in that it has been implicated as a cause of Crohn's disease in humans [4]. Crohn's disease is a chronic inflammatory bowel disorder that commonly affects the terminal ileum but can occur in any part of the gastrointestinal tract from mouth to anus. At present there is no recognised cure but sufferers can experience periods of remission. However, the overall quality of life of the sufferer and their immediate family is low [5]. Although a role, if any, for Map as a contributory factor in Crohn's disease is not proven, the evidence was sufficient for the UK government to advocate a precautionary approach and to attempt to minimise exposure of the public to this organism [6].

Map is known to survive for protracted periods in the environment $[7,8]$, although it is generally considered unable to replicate because of its requirement for mycobactin, an iron-chelating compound, required for replication of the organism outside its natural host. One of the strategies adopted by Map that contributes to its longevity in the environment may be its ability to survive ingestion by protozoa, which are usually bacteriovores (for a review see [9]). Indeed it has been reported that this allows M. avium to acquire a phenotype more pathogenic to humans $[10,11]$. Legionella pneumophila, a known human pathogen, shares the same characteristic except that it is able to multiply within its protozoan host [12]. There is a paucity of published information on the interaction of Map and free-living protozoa that may allow viable intervention strategies to be devised. There is also a lack of information on the protection such an intracellular location might afford against bacteriocidal agents such as chlorine that are used in water treatment operations and food plant cleaning processes.

The work reported here had three objectives: to investigate the uptake of Map by two commonly occurring environmental protozoa, Acanthamoeba castellanii and A. polyphaga; to determine the survival ability of Map when ingested by the two protozoa, and to compare the chlorine resistance of ingested and free-living Map.

\section{Results}

\section{Ingestion of Map by Acanthamoeba spp}

Both qualitative and quantitative methods were employed to assess if ingestion of three Map strains by the two Acanthamoeba spp. occurred. Intracellularly located Map were initially visualised by acid-fast staining of aliquots of co-culture after $180 \mathrm{~min}$; acid-fast Map cells staining red and subcellular structures of the amoeba staining blue. Microscopy revealed that numerous Map cells were present within vacuoles within the amoebae (Figure 1a). Figure $1 \mathrm{~b}$ shows an amoeba cell lysed by sonication in the presence of 1\% Tween 80 releasing the ingested Map cells. Enumeration of the Map cells ingested by the two Acanthamoeba spp. revealed that between 4.6-9.1\% and 4.9$8.3 \%$ of the initial spiked Map populations were taken up
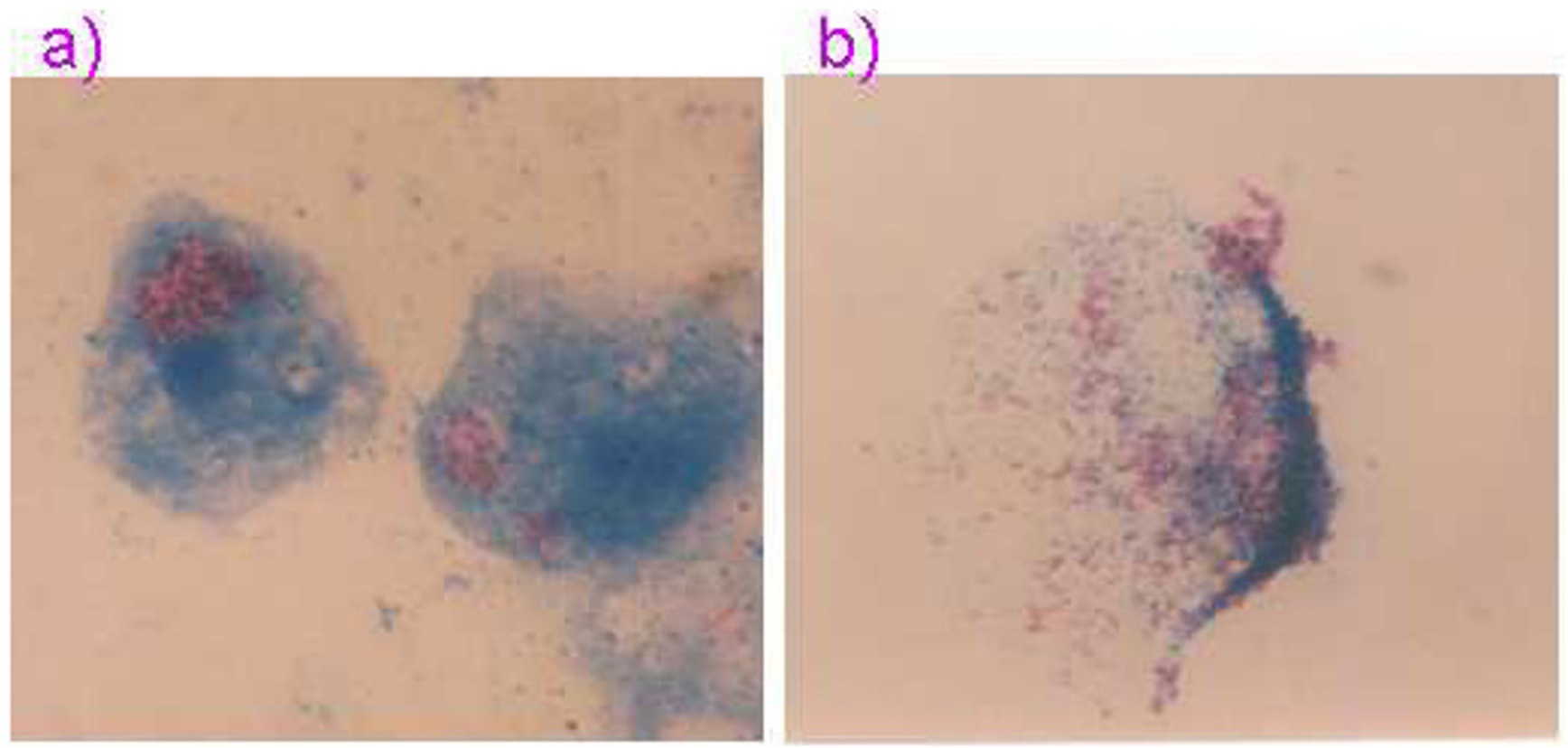

\section{Figure I}

Acid-fast stained smear of (a) co-culture of Map and A. castellanii after $3 \mathrm{~h}$ at $25^{\circ} \mathrm{C}$ showing Map located within vacuole of amoeba cell, and (b) Acanthamoeba cell lysed by sonication in the presence of $1 \%$ Tween 80 releasing ingested Map. 
by A. castellanii and A. polyphaga, respectively, with only minor differences between the three Map strains studied.

\section{Survival of Map within Acanthamoeba spp. for extended periods}

When Map NCTC 8578 was incubated at $25^{\circ} \mathrm{C}$ in co-culture with either $A$. castellanii or $A$. polyphaga for a longer period (up to $24 \mathrm{~d}$ ), the intracellular Map counts did not alter significantly within either Acanthamoeba sp. during the first 7 days of incubation (Figure 2). However, between 7 and 24 days incubation there was a significant $1-1.5 \log _{10}$ increase in numbers of intracellular Map $(\mathrm{P}<$ 0.001). Co-culture was not followed beyond $24 \mathrm{~d}$.

\section{Comparative chlorine resistance of free and internalised Map}

A significant difference in the chlorine resistance of Map harboured within protozoa (i.e. ingested Map) and free Map was observed at all chlorine concentrations and contact times ( $\mathrm{p}<0.001)$. Ingested Map was found to be more resistant to chlorination than free Map overall. The greatest reduction in numbers of ingested Map achieved by exposure to the highest chlorine concentration $(2 \mu \mathrm{g} / \mathrm{ml})$ for the longest contact time (30 $\mathrm{min}$ ) was $0.94 \log _{10}$ reductions, whereas under the same conditions a reduction of $1.73 \log _{10}$ was achieved for free Map (Table 1). Overall, chlorine concentration was found to have a significant effect on inactivation of Map ( $\mathrm{p}<0.05)$, irrespective of whether they were intracellularly located or free, whereas chlorine contact time did not have a significant effect on Map inactivation ( $\mathrm{p}=0.342$ ).

\section{Discussion}

This study has demonstrated that Map is not only able to survive ingestion by $A$. castellanii and A. polyphaga, but that

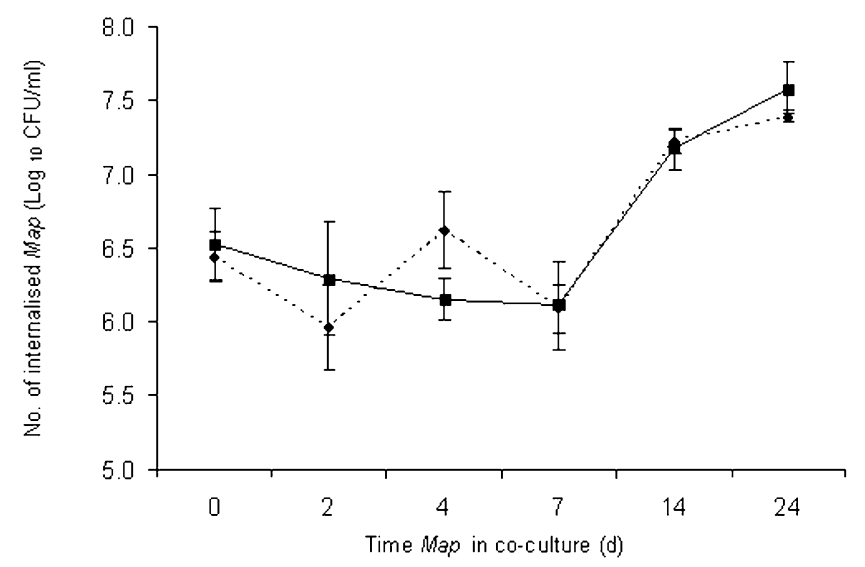

Figure 2

Survival of Map NCTC 8578 after co-culture with Acanthamoeba castellanii (dashed line) and $A$. polyphaga (solid line) for up to 24 days at $25^{\circ} \mathrm{C}$. the intracellular location appears to provide an environment where multiplication of Map can occur and protection from the effects of chlorine is afforded. Our findings in relation to ingestion capability and trends in survival of Map within amoeba following ingestion are similar to those reported recently by Mura et al. [13] for the interaction of bovine and human strains of Map with A. polyphaga. Mura et al. [13] enumerated the number of Map cells in harvested amoebae by quantitative real-time PCR and reported that between 2.5 and 11\% of spiked Map populations were ingested by $A$. polyphaga. In the present study the number of Map within harvested amoebae was quantified by using a published formula [14] which relates BACTEC growth index readings and detection time to numbers of viable Map present, yet the ingestion figures obtained were within the same range as Mura et al. [13] at between 4.6 and 9.1\% for both Acanthamoeba spp. Mura et al. [13] suggested that perhaps amoebae may only be able to take the mycobacteria up as single organisms and not as clumps. Figure 1(a) shows many Map cells concentrated within the vacuole of $A$. castellanii after 3 hours in co-culture at $25^{\circ} \mathrm{C}$. Unfortunately, whether these were taken up as individual cells or as clumps of cells cannot be determined. Interestingly, auramine-rhodamine stained smears of 24 month old co-cultures of A. polyphaga fed with extracts of human Crohn's disease tissue examined by Mura et al. [13] revealed Map present throughout the cytoplasm of the amoeba (i.e. not just confined to the vacuole as in this study) or where the amoebae had undergone encystment Map were peripherally located.

In this study Map clearly demonstrated an ability to survive ingestion by both Acanthamoeba spp., and an increase in Map numbers occurred after an initial 'lag' period of around $7 \mathrm{~d}$ when co-culture was followed for a period of $24 \mathrm{~d}$ (Figure 2). This is also in accord with the findings of Mura et al. [13] who observed a similar length 'lag' period ( $8 \mathrm{~d}$ ) before multiplication (approx. $1 \log _{10}$ increase in numbers) of Map within A. polyphaga between 8 and 12 days. Since Map is a very slow-growing bacterium it is perhaps not surprising that it required an extended period of adaptation to its new intracellular environment before replication commenced. What is unexpected, however, is how Map multiplied at all in the absence of adventitious mycobactin. Replication of the closely-related M. avium following phagocytosis by A. castellanii at temperatures as low as $24^{\circ} \mathrm{C}$ has previously been reported [10], so it is not unexpected that Map behaves in a similar fashion to $M$. avium and, indeed, other mycobacteria studied previously [15]. The observation of the persistence of both M. avium and Map in the outer walls of the double-walled cysts of A. polyphaga $[13,16]$ indicates that Map can also survive encystment which would further prolong its survival in extreme environmental conditions. The above studies provide clear evidence of interaction between Map and 
Table I: Impact of chlorine concentration $(0.5, I$ and $2 \mu \mathrm{g} / \mathrm{ml})$ and contact time ( 15 and $30 \mathrm{~min})$ on inactivation of free and $A$. polyphaga-ingested Map NCTC 8578 in water.

\begin{tabular}{ccccc}
\hline $\begin{array}{c}\text { Chlorine concentration } \\
(\mu \mathrm{g} / \mathrm{ml})\end{array}$ & \multicolumn{2}{c}{15 min contact time } & 30 min contact time \\
\cline { 2 - 5 } & Free Map & Ingested Map & Free Map & Ingested Map \\
& & & Log reduction (mean \pm s.d.) & $0.16 \pm 0.04$ \\
& & $0.22 \pm 0.25$ & $0.78 \pm 0.65$ & $0.63 \pm 0.53$ \\
1 & $1.27 \pm 0.75$ & $0.51 \pm 0.17$ & $1.72 \pm 1.05$ & $0.94 \pm 0.56$ \\
\hline
\end{tabular}

protozoa at ambient laboratory temperatures $\left(20-25^{\circ} \mathrm{C}\right)$. Numerous invertebrate and protozoal species have been shown to be present in surface water in Australia [17] so there is certainly scope for such interaction to take place. However, further research will be required to confirm whether interaction occurs between Map and protozoa at lower temperatures that may be more representative of natural environmental conditions, certainly in temperate climates.

The bactericidal effect of chlorine on free Map in water was studied previously in our laboratory [18]. $\log _{10}$ reductions in the range 1.32-2.82 were observed for Map strains NCTC 8578 (bovine) and ATCC 43015 (human isolate) during that study when the same chlorine concentrations and contact times were employed as in the present study. $\log _{10}$ reductions observed for free Map NCTC 8578 during the present study fell broadly within the same range $\left(0.78-1.73 \log _{10}\right) . \log _{10}$ reductions achieved with ingested Map were much lower (0.16-0.94 $\log _{10}$ ) indicating enhanced chlorine resistance when Map was taken up by A. polyphaga. The elevated chlorine resistance of ingested Map is perhaps not unexpected, given that this has previously been observed for coliforms and other bacterial pathogens within protozoa [19]. Enhanced resistance of Map to other chemical stressors when taken up by amoebae is also a possibility given that co-culture of $M$. avium with A. castellanii reduced the effectiveness of the antimicrobials rifabutin, azithromycin and clarithromycin [20].

\section{Conclusion}

The demonstrated ability of Map to survive ingestion by Acanthamoeba spp. in the laboratory situation and subsequently multiply clearly illustrates a potential survival and dissemination strategy for this animal pathogen, which may also potentially be implicated in human disease, to use in the natural environment. The enhanced chlorine resistance when ingested by protozoa has clear implications with regard to ensuring the efficacy of chlorination processes during water treatment in order to minimise exposure of the public to this potential pathogen.

\section{Methods}

\section{Culture preparation}

Axenic cultures of Acanthamoeba castellanii CCAP 1501/1B and $A$. polyphaga CCAP 1501/3B were maintained in tissue culture flasks containing $10 \mathrm{ml}$ proteose peptone glucose (PPG) medium incubated at $25^{\circ} \mathrm{C}$ and passed every $4-5$ days (volume of passage 1:10). The flasks were incubated flat for optimum growth of the amoebae. The PPG medium consisted of proteose peptone $(15 \mathrm{~g} / \mathrm{l}$; Oxoid Unipath, Basingstoke, Hampshire, UK) and glucose (18 g/ l; Sigma Ltd., Gillingham, UK). The PPG medium was made to volume with amoeba saline solution (ASS) instead of water. The ASS consisted of two stock solutions viz. solution 1, $\mathrm{NaCl} 24 \mathrm{~g} / \mathrm{l}, \mathrm{MgSO}_{4} \cdot 7 \mathrm{H}_{2} \mathrm{O} 0.8 \mathrm{~g} / \mathrm{l}$, $\mathrm{CaCl}_{2} \cdot 6 \mathrm{H}_{2} \mathrm{O} 1.2 \mathrm{~g} / \mathrm{l}$; solution 2, $\mathrm{Na}_{2} \mathrm{HPO}_{4} 28.4 \mathrm{~g} / \mathrm{l}$, $\mathrm{KH}_{2} \mathrm{PO}_{4} 27.2 \mathrm{~g} / \mathrm{l}$. The final ASS consisted of $5 \mathrm{ml}$ each of stock solutions 1 and 2 and the mixture made to volume (1 litre) using glass-distilled water.

The three Map strains used in this study - NCTC 8578, B2 and ATCC 19698 - had been maintained on Protect cryobeads (Technical Service Consultants, Heywood, UK) at $-80^{\circ} \mathrm{C}$ in order to preserve genetic integrity since entering our laboratory, and had not been repeatedly sub-cultured. For each experiment a working Map culture was generated by inoculating a cryobead into Middlebrook $7 \mathrm{H} 9$ broth with OADC supplement (oleic acid, albumin, dextrose, catalase; Becton Dickinson, Oxford, UK) and $2 \mu \mathrm{g} / \mathrm{ml}$ mycobactin J (Synbiotics Europe SAS, Lyon, France) and incubating for $6-7$ weeks at $37^{\circ} \mathrm{C}$.

\section{Ingestion capacity experiment}

Acanthamoeba castellanii and A. polyphaga were grown in PPG at $25^{\circ} \mathrm{C}$ for 4 days after which the medium was poured off gently so as not to disturb the bottom surfaceattached protozoa. The monolayers were washed gently with ASS once and the monolayer re-suspended in fresh ASS before being incubated overnight at $25^{\circ} \mathrm{C}$ to starve the protozoa. A working culture of Map was centrifuged at $2500 \mathrm{~g}$ for $20 \mathrm{~min}$, the pellet washed twice with ASS and finally re-suspended in ASS to give a final cell concentration of approximately $10^{7} \mathrm{CFU} / \mathrm{ml}$ as determined by nephelometry and also subsequent culture in BACTEC 
12B medium (Becton Dickinson) supplemented with 2 $\mu \mathrm{g} / \mathrm{ml}$ mycobactin J. The number of Map incubated with the Acanthamoeba spp. was derived from the BACTEC growth index readings using the published formula of Lambrecht et al. [14]. The starved A. castellanii and A. polyphaga cultures were resuspended by tapping the flasks and the resulting cell suspensions counted using a haemocytometer. The respective protozoan cultures were centrifuged at $400 \mathrm{~g}$ for $5 \mathrm{~min}$ and the pellets re-suspended with the Map-ASS suspensions $(10 \mathrm{ml})$ at a multiplicity of infection (MOI) of $10 \mathrm{Map}$ to 1 Acanthamoeba cell and incubated at $25^{\circ} \mathrm{C}$ for $180 \mathrm{~min}$. Following incubation the Map-ASS suspension was decanted off and the monolayer washed twice with $10 \mathrm{ml}$ ASS in order to minimise carryover of free Map. The protozoan monolayers, after the final washing, were resuspended in $10 \mathrm{ml}$ phosphatebuffered saline supplemented with $1 \% \mathrm{v} / \mathrm{v}$ Tween 80 (PBS-T, pH 7.4; Sigma, Poole, UK) and incubated at $25^{\circ} \mathrm{C}$ for $10 \mathrm{~min}$ before being sonicated $(2 \times 30 \mathrm{~s}$ at $50 \%$ intensity with a $10 \mathrm{~s}$ interval between bursts) to lyse the amoebae. The lysate was centrifuged at $2,500 \mathrm{~g}$ for $20 \mathrm{~min}$ and the pellet re-suspended in $10 \mathrm{ml}$ PBS-T and decimally diluted. The dilutions $(0.5 \mathrm{ml}$ of each) were inoculated into BACTEC $12 \mathrm{~B}$ medium, incubated at $37^{\circ} \mathrm{C}$ and read regularly on a BACTEC 460 machine. Intracellular Map counts were derived from the BACTEC growth index readings using the published formula of Lambrecht et al. [14]. This method of quantifying Map has been employed in published studies assessing acid resistance [21] and growth of sheep strains of Map [22]. Quantitative data derived using this equation must be regarded as approximate since Map cells in different physiological states may exhibit different growth responses in the BACTEC culture system. Three replicate runs of this experiment were performed with three strains of Map.

\section{Visualisation of ingested Map by acid-fast microscopy}

A $10 \mu \mathrm{l}$ sample of the protozoa/Map co-culture was spotted onto a glass slide and dried for 5 minutes at $70^{\circ} \mathrm{C}$. The slide was flooded with basic carbol fuschin stain for 15 minutes. The slide was rinsed and flooded with $3 \%$ acidalcohol (3.0 ml concentrated hydrochloric acid (technical grade) in $97 \mathrm{ml}$ of $95 \% \mathrm{v} / \mathrm{v}$ ethanol) for $1 \mathrm{~min}$. The slide was rinsed and flooded with a $1.0 \mathrm{mg} / \mathrm{ml}$ solution of methylene blue for $1 \mathrm{~min}$, which allowed the margins and sub-cellular structure of the amoebae to be visually distinguished. The slide was examined using a Zeiss Axiophot compound microscope under an objective lens $(\times 100)$.

\section{Survival of ingested Map}

Acanthamoeba and Map NCTC 8578 co-cultures in PPG medium were prepared as described above and incubated at $25^{\circ} \mathrm{C}$ for up to 24 days. Both Acanthamoeba spp. were studied but only one Map strain. After 7, 14 and 21 days the PPG medium was replaced to prevent the amoeba encysting [18]. Sub-samples $(1 \mathrm{ml})$ of co-culture were removed after $3 \mathrm{~h}(0), 2,4,7,14$ and 24 days, centrifuged at 2,500 $\mathrm{g}$ for $20 \mathrm{~min}$ and the pellet re-suspended in PBS$\mathrm{T}(10 \mathrm{ml})$. The suspension was lysed (as described above) and the lysate decimally diluted and inoculated into BACTEC 12B medium and growth monitored and Map counts derived after each incubation time as before. The means of three replicate runs were compared by ANOVA.

\section{Comparative resistance of intracellular and extracellular Map to chlorine}

A chlorine stock solution (1:1000 dilution) was prepared using Chloros (approx. 10\% available chlorine) using distilled reverse osmosis (DRO) water. This was used to prepare test chlorine solutions containing 0, 0.5, 1.0 and 2.0 $\mu \mathrm{g} / \mathrm{ml}$ free chlorine. The free chlorine concentrations were confirmed using the $\mathrm{N}, \mathrm{N}$-diethyl-p-phenylenediamine ferrous titrimetric method [23]. The test solutions were freshly prepared before each experimental run and were held at room temperature for no longer than $5 \mathrm{~min}$ before inoculation. A starved co-culture of Map and A. polyphaga was prepared as before (incubated for $180 \mathrm{~min}$ ) along with individual control cultures of Map and A. polyphaga alone. The prepared test chlorine solutions $(10 \mathrm{ml})$ were inoculated with co-culture and control cultures and incubated at $20^{\circ} \mathrm{C}$ for the respective contact times of 15 and $30 \mathrm{~min}$. After the appropriate contact time had elapsed the chlorine was neutralised with $1 \mathrm{ml}$ of $1 \% \mathrm{w} / \mathrm{v}$ sodium thiosulphate before the sample was centrifuged at $2500 \mathrm{~g}$ for $20 \mathrm{~min}$ and the pellet resuspended in $1 \mathrm{ml}$ PBS-T. At this point samples originally inoculated with a co-culture of amoebae and Map (i.e. ingested Map) were lysed by sonication (as described for ingestion capacity experiment) before dilution, whereas samples inoculated with Map only (i.e. free Map) were diluted without sonication. Appropriate decimal dilutions were prepared in Maximum Recovery Diluent (Oxoid) and $500 \mu \mathrm{l}$ of each dilution was inoculated into BACTEC $12 \mathrm{~B}$ medium, incubated at $37^{\circ} \mathrm{C}$, read regularly as before and Map counts derived using the published formula [14]. The differences in resistance between amoeba-ingested and free Map at varying chlorine concentrations and contact times were compared using ANOVA.

\section{Authors' contributions}

LW carried out the laboratory experiments, acquired and analysed the data, and drafted the manuscript. IG provided training to LW in the culture of Map and critically revised the manuscript. MR conceived of the study, participated in its design and coordination and helped to draft the manuscript. All authors read and approved the final manuscript.

\section{Acknowledgements}

The authors wish to thank Queen's University Belfast, for the award of a Thomas Henry Scholarship to LW, and Mr Randall Scott of the Northern 
Ireland Drinking Water Inspectorate and Mr Tom Adamson and Mr Sam Irwin of the Northern Ireland Water Service for helpful advice.

\section{References}

I. Clarke C): The pathology and pathogenesis of paratuberculosis in ruminants and other species. J Comp Path 1997, I | 6:2 |7-26I.

2. Chiodini RJ, van Kruiningen HJ, Merkal RS: Ruminant paratuberculosis (Johne's disease): the current status and future prospects. Cornell Vet 1984, 74:218-262.

3. Kuehnel MP, Goethe R, Habermann A, Mueller E, Rohde M, Griffiths $G$, Valentin-Weigand P: Characterisation of the intracellular survival of Mycobacteruim avium ssp. paratuberculosis: phagosomal pH and fusogenicity in $\mathbf{J 7 7 4}$ macrophages compared with other mycobacteria. Cell Microbiol 200I, 3:55 I-566.

4. Chiodini RJ, Rossiter CA: Paratuberculosis: a potential zoonosis? Vet Clin N Amer 1996, I 2:457-467.

5. Irvine EJ: Quality of life in inflammatory bowel disease and other chronic bowel diseases. Scand J Gastroenterol 1996, 3 I (suppl 22 I):990-995.

6. Rubery E: A review of the evidence for a link between exposure to Mycobacterium paratuberculosis (MAP) and Crohn's disease (CD) in humans. A Report for the United Kingdom Food Standards Agency 200 l.

7. Whittington RJ, Marshall DJ, Nicholls PJ, Marsh IB, Redacliff LA: Survival and dormancy of Mycobacterium avium subsp. paratuberculosis in the environment. Appl Environ Microbiol 2004, 70:2989-3004.

8. Rowe MT, Grant IR: Mycobacterium avium ssp. paratuberculosis and its potential survival tactics. Lett Appl Microbiol 2006, 42:305-3II.

9. Molmeret M, Horn M, Wagner M, Santic M, Abu Kwaik Y: Amoebae as training grounds for intracellular bacterial pathogens. Appl Environ Microbiol 2005, 71:20-28.

10. Cirillo JD, Falkow S, Tompkins LS, Bermudez LE: Interaction of Mycobacterium avium with environmental amoebae enhances virulence. Infect Immun 1997, 65:3759-3767.

II. Hermon-Taylor J: Mycobacterium avium subspecies paratuberculosis the nature of the problem. Food Control 2000, I 2:331-334.

12. Abu Kwaik Y, Gao LY, Stone BJ, Venkataraman C, Harb OS: Invasion of protozoa by Legionella pneumophila and its role in bacterial ecology and pathogenesis. Appl Environ Microbiol 1998, 64:3127-3133

13. Mura M, Bull TJ, Evans H, Sidi-Boumedine K, McMinn L, Rhodes G, Pickup R, Hermon-Taylor J: Replication and long-term persistence of bovine and human strains of Mycobacterium avium subsp.paratuberculosis with Acanthamoeba polyphaga. Appl Environ Microbiol 2006, 72:854-859.

14. Lambrecht RS, Carriere JF, Collins MT: A model foranalysing growth kinetics of a slowly growing Mycobacterium sp. Appl Environ Microbiol 1988, 54:910-916.

15. Krishna-Prasad BN, Gupta SK: Preliminary report on the engulfment and retention of mycobacteria by trophozoites ofaxenically grown Acanthamoeba castellanii Douglas, 1930. Curr Sci 1978, 47:245-247.

16. Steinert M, Birkness K, White E, Fields B, Quinn F: Mycobacterium avium bacilli grow saprozoically in coculture with Acanthamoeba polyphaga and survive within cyst walls. Appl Environ Microbiol 1998, 64:2256-226I.

17. Whittington RJ, Marsh IB, Reddacliff LA: Survival of Mycobacterium avium subsp. paratuberculosis in dam water and sediment. Appl Environ Microbiol 2005, 71:5304-5308.

18. Whan LB, Grant IR, Ball HJ, Scott R, Rowe MT: Bactericidal effect of chlorine on Mycobacterium paratuberculosis in drinking water. Lett Appl Microbiol 200I, 33:227-23I.

19. King $\mathrm{CH}$, Shotts EB, Wooley RE, Porter KG: Survival of coliforms and bacterial pathogens within protozoa during chlorination. Appl Environ Microbiol 1988, 45:3023-3033.

20. Miltner EC, Bermudez LE: Mycobacterium avium grown in Acanthamoeba castellanii is protected from the effects of antimicrobials. Antimicrob Agents Chemother 2000, 44:1990-1994.

21. Sung NM, Collins MT: Variation in resistance of Mycobacterium paratuberculosis to acid environments as a function of culture medium. Appl Environ Microbiol 2003, 69:6833-6840.
22. Reddacliff LA, Nicholls PJ, Vadali A, Whittington RJ: Use of growth indices from radiometric culture for quantification of sheep strains of Mycobacterium avium subsp. paratuberculosis. ApP Environ Microbiol 2003, 69:3510-35I6.

23. American Public Health Association: Standard Methods for the Examination of Water and Wastewater 16th edition. Washington DC: American Public Health Association; 1993.
Publish with Bio Med Central and every scientist can read your work free of charge

"BioMed Central will be the most significant development for disseminating the results of biomedical research in our lifetime. "

Sir Paul Nurse, Cancer Research UK

Your research papers will be:

- available free of charge to the entire biomedical community

- peer reviewed and published immediately upon acceptance

- cited in PubMed and archived on PubMed Central

- yours - you keep the copyright

Submit your manuscript here:

http://www.biomedcentral.com/info/publishing_adv.asp
BioMedcentral 